\title{
Like father like son? Sons of patients of European or Indian origin with coronary artery disease reflect their parents' risk factor patterns
}

\author{
N Shaukat, D P de Bono, D R Jones
}

\begin{abstract}
Objective-To investigate the extent to which risk factor patterns associated with coronary artery disease (CAD) in patients of Indian origin and in those of North European origin undergoing coronary angiography for suspected angina were reflected in their apparently healthy sons aged 15-30 years.

Design-Prospective study in which risk markers were measured in patients of

disease in their parents, both for genetically determined factors such as $L p(a)$ lipoprotein and environmentally influenced factors such as insulin and cholesterol. Health promotion measures aimed at reducing the prevalence of $\mathrm{CAD}$ should include the adolescent and young adult populations, particularly those with a family history of CAD, or who are from ethnic communities in which this diagnosis is prevalent.
\end{abstract} Indian origin and in matched European patients undergoing angiography and in their sons.

Setting-Patients attending a regional cardiac centre and their families.

Patients-102 consecutive male patients of Indian origin undergoing diagnostic coronary angiography for suspected angina and 89 of their sons aged between 15 and 30 years; 102 age matched male European patients and 82 sons.

Main outcome measures-Father son correlations for risk markers predicting the severity of parental CAD; differences in mean levels of these markers between young males of Indian origin and those of North European origin.

Results-Lp(a) lipoprotein, total cholesterol, and serum insulin were independent predictors of the severity of CAD in patients of Indian origin and in those of North European origin. In both groups, there was strong correlation between paternal and filial serum insulin $(r=0.41$ Indian origin, $r=0.49$ North European, $P<0.001)$, Lp(a) lipoprotein $(r=0.44$ Indian origin, $r=0.48$ North European, $P<0.001)$, and total cholesterol $(r=0.39$ Indian origin, $r=0.45$ North European, $P<0.001)$ concentrations, and the risk factor profiles of the sons were predictive of CAD severity in their fathers. Sons of patients of Indian origin had significantly higher serum insulin (Indian origin 14.3 mU/l $v$ North European $8.4 \mathrm{mU} / \mathrm{l}, \mathrm{P}=$ 0.002 ) and $L p(a)$ lipoprotein (Indian origin $19.1 \mathrm{mmol} / \mathrm{l} v$ North European 10.5 $\mathrm{mmol} / \mathrm{l}, P=0.001$ ) concentrations than sons of patients of North European origin.

Conclusions-Apparently healthy young men aged 15-30 years from either ethnic community already reflect risk marker patterns associated with coronary artery
(Br Heart F 1995;74:318-323)

Keywords: coronary artery disease; risk factor patterns in fathers and sons; ethnic populations.

All groups of Indian origin in the United Kingdom have an increased incidence and prevalence of, and mortality from, coronary artery disease (CAD). ${ }^{1}$ Much of the current literature concerning these populations refers to people over the age of 40 years, most of whom were born outside the United Kingdom. It has been emphasised that if current trends in mortality associated with CAD continue, there may be a threefold increase in standardised death rates in the United Kingdom community of Indian origin by the year $2005 .^{2}$ It is important to know to what extent increased risks can be extrapolated to the next generation of individuals of Indian origin, who were born and raised in the United Kingdom.

We have previously shown a consistent association of conventional coronary risk factors with severity of angiographically assessed CAD in patients of Indian origin and in those of North European origin undergoing diagnostic coronary angiography. ${ }^{3}$ In the present study we have measured an extended range of risk factors for CAD in new cohorts of patients of Indian origin and of North European origin undergoing angiography for suspected angina, and also in their "healthy" male offspring aged 15-30 years. Our aims were to determine the relation of risk markers with the severity of CAD in samples of patients of Indian origin and of those of North European origin, to evaluate differences between young males of Indian origin and of North European origin in respect of the same risk markers, and finally to ascertain the extent to which risk marker differences within 
each group of young relatives is explicable in terms of their parents' risk factor profile and severity of CAD.

\section{Patients and methods}

Some 102 of 109 consecutive male patients of Indian origin undergoing diagnostic coronary angiography for suspected angina at our institution between July 1992 and August 1993 were recruited into the study. A total of 102 patients of North European origin investigated for suspected angina over the same period were matched for age and symptom duration with the patients of Indian origin. Ethnicity of the Indian origin group (Gujerati or Punjabi) was established by grandparental origin. Route of migration to the United Kingdom and religion were also recorded. Sons aged 15-30 years of patients in either group were approached and invited to participate in the study. Some 89 offspring of Indian origin (related to 72 patients of Indian origin) and 82 offspring of North European origin (related to 74 patients) were recruited. Six sons of Indian origin and four sons of North European origin declined to participate in the study.

Severity of parental CAD was assessed from the numbers of vessels involved and coronary lesions observed. Coronary arteriograms were classified in three groups: minimal disease (no diameter stenosis $>70 \%$ in any vessel), single vessel disease (stenosis > $70 \%$ in one vessel only), and multivessel disease (stenosis $>70 \%$ in two or more vessels). In addition, angiograms were scored for extent of coronary disease by the method of Hughes et $a l^{4}{ }^{4}$ which allocates a numerical score based on the number and severity of lesions. Coronary arteriograms were assessed by two observers blinded to patient identity and unaware of biochemical or demographic data.

Demographic details, medical histories, smoking habits, and alcohol intake were recorded at interview with each patient or son. Smoking was recorded as current, ex-smoker (non-smoker for at least six months) or never. Previous medical histories of diabetes or hypertension, or a history of CAD in a first degree relative were also noted. Usual consumption of alcoholic beverages was recorded in standard units. Blood pressure was measured in the sitting position $15 \mathrm{~min}$ after the start of the interview and at the end of the interview, and results were averaged. A random zero sphygmomanometer was used, and phase $\mathrm{V}$ taken for the diastolic measurement. Weight was measured to the nearest $0.1 \mathrm{~kg}$ and height to the nearest $0 \cdot 1 \mathrm{~cm}$. Body mass index was calculated as weight in kilograms divided by the square of height in metres. Waist and hip circumference measurements were made to the nearest $0.1 \mathrm{~cm}$ with a tape measure incorporating a spring balance to ensure consistency of tension. The waist was measured as the smallest circumference between the costal margin and the iliac crest, and hip measurements were taken at the level of the most lateral point on the greater trochanter.

Venous blood samples were taken between 900 and 1000 am after an overnight fast. Samples from patients were taken six weeks after angiography. Samples were treated with fluoride/EDTA for glucose estimation and collected into dry containers for determination of serum cholesterol and high density lipoprotein (HDL) cholesterol, serum nonesterified fatty acid, serum triglycerides, serum insulin, serum apolipoprotein $B$, and serum Lp(a) lipoprotein. Plasma or serum samples were separated promptly and stored at $-70^{\circ} \mathrm{C}$. Total cholesterol, HDL cholesterol, and triglycerides were determined by the CHOD-PAP method (Boehringer Mannheim, Germany). Serum apolipoprotein $B$ concentration was measured by a rate immunoephelometric method $^{5}$ using the Beckmann array, with antisera and standards supplied by the manufacturer (Beckmann Instruments, Palo Alto, California, USA). The method was repeatedly calibrated against a secondary serum standard the apolipoprotein B concentration of which was determined using a primary standard of density $1.040-1.053 \mathrm{~g} / \mathrm{ml}$ isolated by ultracentrifugation. ${ }^{6} \mathrm{Lp}$ (a) lipoprotein concentrations were measured using a two site immunoradiometric method (Pharmacia, Uppsala, Sweden). Nonesterified fatty acid was measured enzymatically (Wako Chemicals, Germany). Serum insulin was measured by radioimmunoassay ${ }^{7}$ using a double antibody solid phase technique (Pharmacia, Uppsala, Sweden), and plasma glucose by the GOD-PAP method (Boehringer Mannheim, Germany). Quality control standards were used for all techniques, and assays were performed within four weeks of taking the sample.

Triglyceride, HDL cholesterol, insulin, $\mathrm{Lp}$ (a) lipoprotein, and non-esterified fatty acid concentrations, and coronary stenosis scores were logarithmically transformed to normalise their distributions before analysis of variance (with Newman Keuls test for multiple group comparisons). Distributions of categorical variables were compared using the $\chi^{2}$ test. Serum concentrations and blood pressure were adjusted using age and body mass index ${ }^{8}$ as covariates; adjusted values were compared and are shown in the tables. Analysis was performed using SPSS software (Statistical Package for Social Sciences, Release 5).

\section{Results}

COMPARISON BETWEEN PATIENTS OF INDIAN ORIGIN AND NORTH EUROPEAN ORIGIN

The mean (range) age of the patients of Indian origin was $54.7(32-72)$ years and of those of North European origin 53.7 (35-76). Table 1 gives the physical, behavioural, and angiographic features of the patients of Indian origin and of those of North European origin. There were 33 Gujerati Hindus, 14 Gujerati Muslims, 30 Punjabi Sikhs, and 25 Punjabi Muslims in the Indian origin group. 
Patients of Indian origin had more widespread coronary disease and greater waist hip ratios; patients of North European origin drank more alcohol, were more likely to be current smokers, and were more likely to have single vessel disease. Glucose, total cholesterol, HDL cholesterol, and triglyceride concentrations, and

Table 1 Physical, behavioural, and angiographic details of patients of Indian origin (IO) and of those of North European (NE) origin with suspected angina

\begin{tabular}{|c|c|c|}
\hline Variable & $I O(n=102)$ & $N E(n=102)$ \\
\hline $\begin{array}{l}\text { Age (years) } \\
\text { Body mass index } \\
\left(\mathrm{kg} / \mathrm{m}^{2}\right)\end{array}$ & $\begin{array}{l}54 \cdot 7(53 \cdot 2-56 \cdot 2) \\
25 \cdot 4(24 \cdot 5-26 \cdot 3)\end{array}$ & $\begin{array}{l}53 \cdot 7(52 \cdot 4-55 \cdot 0) \\
26 \cdot 3(25 \cdot 7-26 \cdot 9)\end{array}$ \\
\hline $\begin{array}{l}\text { Waist hip ratio } \\
\text { Manual worker (\%) } \\
\text { Current smokers (\%) } \\
\text { Alcohol consumption } \\
\text { (U/week) }\end{array}$ & $\begin{array}{l}0.94(0.92-0.96) \\
54(47-61) \\
44(39-49) \\
6.41(4.96-7.86)\end{array}$ & $\begin{array}{l}0 \cdot 89(0 \cdot 87-0.91) \\
55(49 \%-61) \\
59(54-63) \\
9 \cdot 00(7 \cdot 67-10 \cdot 3)\end{array}$ \\
\hline $\begin{array}{l}\text { Normal coronaries (\%) } \\
\text { Single vessel disease } \\
(\%)\end{array}$ & $\begin{array}{l}26(20-29) \\
28(23-33)\end{array}$ & $\begin{array}{l}19(14-22) \\
48(40-56)\end{array}$ \\
\hline $\begin{array}{l}\text { Multivessel disease } \\
\text { (\%) }\end{array}$ & $46(38-54)$ & $33(25-41)$ \\
\hline $\begin{array}{l}\text { Coronary atheroma } \\
\text { score }\end{array}$ & $18 \cdot 3(16 \cdot 9-19 \cdot 7)$ & $14 \cdot 9(13 \cdot 6-16 \cdot 2)$ \\
\hline Left ventricular score & $6.9(6.4-7.5)$ & $6 \cdot 8(6 \cdot 3-7 \cdot 2)$ \\
\hline
\end{tabular}

Values are mean or percentage ( $95 \%$ confidence intervals).

Table 2 Blood pressure and biochemical features of patients of Indian origin (IO) and of those of North European (NE) origin

\begin{tabular}{|c|c|c|}
\hline Variable & $I O(n=102)$ & $N E(n=102)$ \\
\hline $\begin{array}{l}\text { Systolic blood pressure }(\mathrm{mm} \mathrm{Hg}) \\
\text { Diastolic blood pressure }(\mathrm{mm} \mathrm{Hg}) \\
\text { Fasting glucose }(\mathrm{mmol} / \mathrm{l}) \\
\text { Insulin (umol/) } \\
\text { Total cholesterol (mmol/l) } \\
\text { High density lipoprotein cholesterol }\end{array}$ & $\begin{array}{c}133 \cdot 3(129 \cdot 5-137 \cdot 1) \\
78 \cdot 0(76 \cdot 5-79 \cdot 4) \\
4 \cdot 6(4 \cdot 2-5 \cdot 1) \\
17 \cdot 6(16 \cdot 4-19) \\
6 \cdot 0(5 \cdot 8-6 \cdot 2)\end{array}$ & $\begin{array}{c}135 \cdot 1(131-138 \cdot 3) \\
79 \cdot 2(76 \cdot 0-82 \cdot 6) \\
4 \cdot 1(3 \cdot 7 \cdot 4 \cdot 6) \\
13 \cdot 5(12 \cdot 4-14 \cdot 8) \\
5 \cdot 9(5 \cdot 7-6 \cdot 2)\end{array}$ \\
\hline $\begin{array}{l}\text { Trimmolyceride (mmol/s) } \\
\text { Apolipoprotein B (mg/dl) } \\
\text { Lp(a) lipoprotein (mg/dl) } \\
\text { Non-esterified fatty acid (mEq/l) } \\
\text { Diabetes (\%) }\end{array}$ & $\begin{array}{l}1 \cdot 1(1 \cdot 0-1 \cdot 1) \\
2 \cdot 2(2 \cdot 0-2 \cdot 3) \\
104 \cdot 7(101 \cdot 1-108 \cdot 19) \\
27 \cdot 2(25 \cdot 8-28 \cdot 5) \\
0 \cdot 67(0.59-0 \cdot 76) \\
29(23-35)\end{array}$ & $\begin{array}{c}1 \cdot 1(1 \cdot 1-1 \cdot 3) \\
2 \cdot 1(2 \cdot 0-2 \cdot 3) \\
113 \cdot 4(108 \cdot 8-118 \cdot 1) \\
19 \cdot 5(18 \cdot 3-20 \cdot 4) \\
0 \cdot 40(0 \cdot 33-0 \cdot 47) \\
14(10-18)\end{array}$ \\
\hline
\end{tabular}

Values are mean or percentage ( $95 \%$ confidence intervals) (adjusted for age and body mass index). blood pressure measurements were similar in the two groups after adjusting for age and body mass index (table 2). Mean apolipoprotein $B$ concentration was higher in patients of North European origin; insulin, $L p(a)$ lipoprotein, and non-esterified fatty acid concentrations were higher in patients of Indian origin. Diabetes mellitus was about twice as prevalent in patients of Indian origin.

Insulin concentration was positively correlated with waist hip ratio, triglycerides, and non-esterified fatty acid in both groups, and more weakly correlated with $\mathrm{Lp}$ (a) lipoprotein, especially in patients of Indian origin (table 3 ). There was a negative correlation between insulin and HDL cholesterol.

Table 4 shows an association between extent of coronary disease and insulin, total cholesterol, triglycerides, and $\mathrm{Lp}$ (a) lipoprotein, and a negative association with HDL cholesterol in patients of Indian origin and in those of North European origin. Waist hip ratio also correlated with the extent of disease in patients of Indian origin and to a lesser extent in those of North European origin. Neither non-esterified fatty acid nor apolipoprotein B correlated with extent of coronary disease in either group, nor was there a clear relation with smoking status (data not shown) or blood pressure.

We further investigated joint associations between potential predictor variables and disease extent by multiple regression analysis using the log transformed coronary score as dependent variable. Potential predictor variables were those with an apparently significant association with coronary score on univariate analysis plus variables such as smoking habit which might be expected on "a priori" grounds to be associated with coronary disease. Variables were entered in order of decreasing strength of univariate correlation. Table 5 summarises the results of multivariate

Table 3 Univariate correlation coefficients of serum insulin, plasma lipids, and blood pressure (adjusted for age and body mass index) in patients of Indian origin (IO) and in those of North European (NE) origin

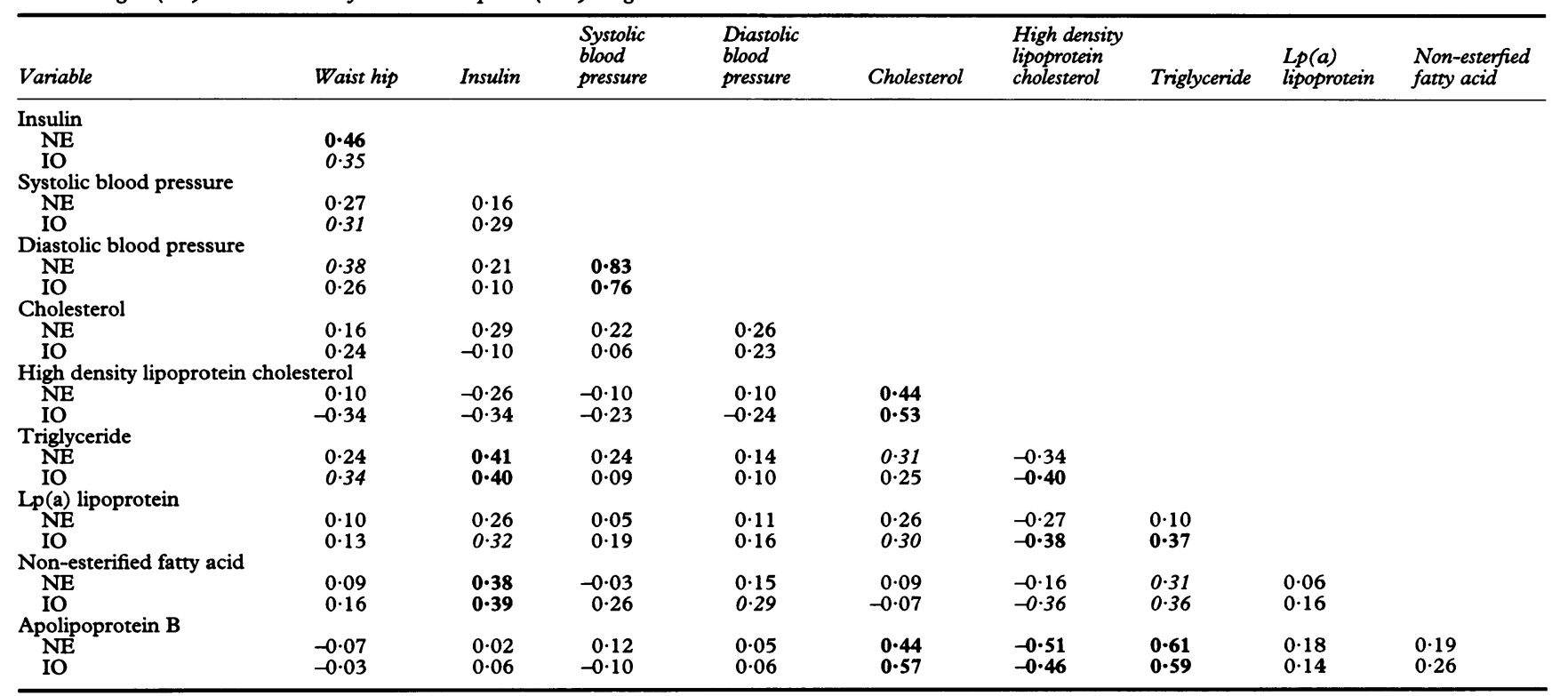

Values in bold indicate $\mathrm{P}<0.001$ and those in italic $\mathrm{P}<0.01$ 
Table 4 Selected variables according to the severity of coronary artery disease (CAD) in patients of Indian origin (IO) and in those of North European (NE) origin (adjusted for age and body mass index)

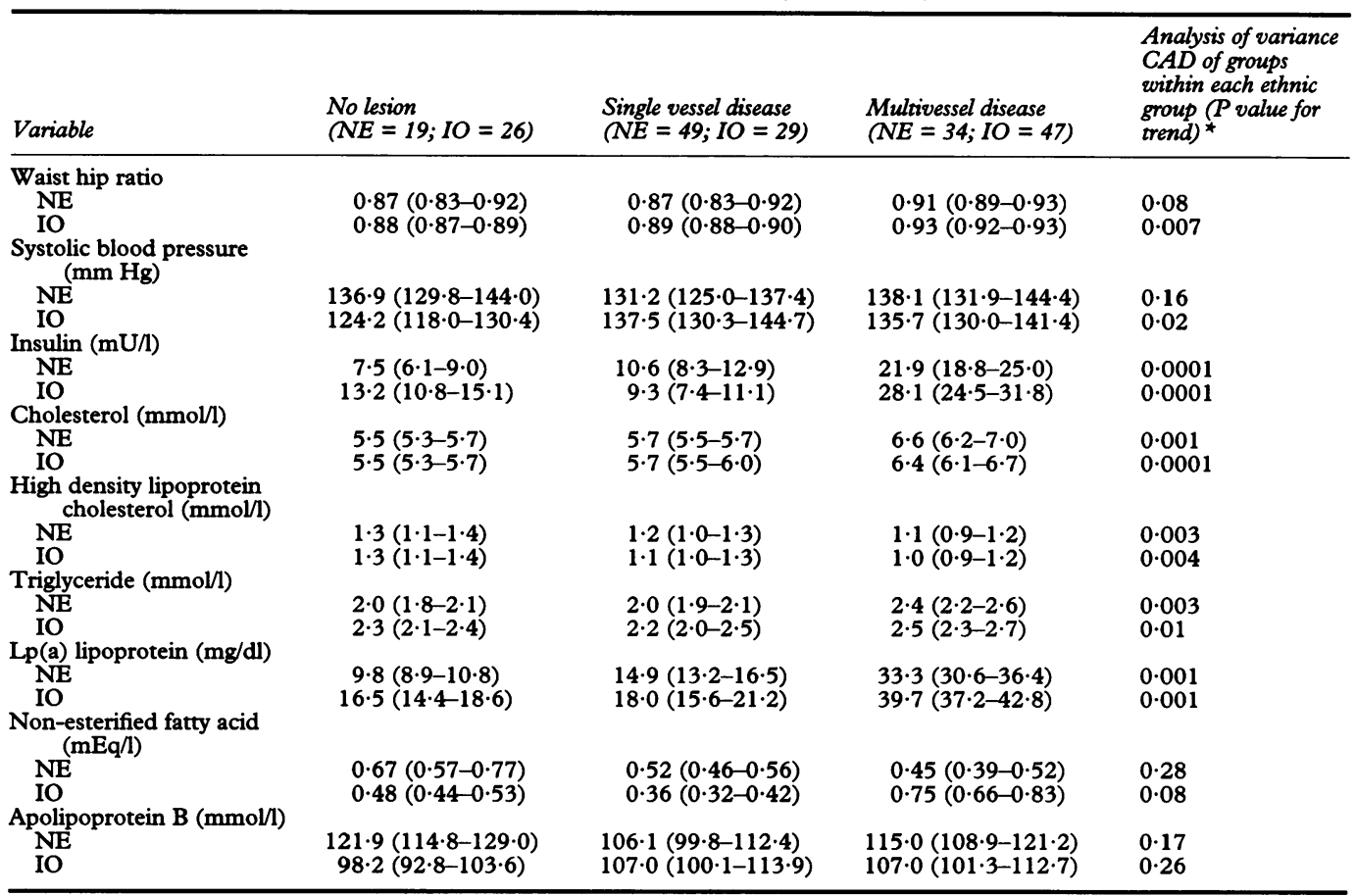

Values are mean (95\% confidence intervals).

${ }^{\star}$ Followed by Newman-Keuls test.

analysis. In each group $\mathrm{Lp}(\mathrm{a})$ lipoprotein, total cholesterol, and insulin contributed independently to the prediction of extensive CAD, irrespective of the order in which the variables were entered. HDL cholesterol in patients of Indian origin and triglyceride concentrations in those of North European origin also contributed.

SONS OF PATIENTS OF INDIAN ORIGIN COMPARED WITH SONS OF PATIENTS OF NORTH EUROPEAN ORIGIN

Eighteen, 30, and 41 of the young Indian origin group were sons of patients with minimal, single vessel, or multivessel disease respectively; the corresponding values in the North

Table 5 Explanatory value of metabolic and physical variables as predictors of the severity of coronary artery disease in patients of Indian origin (IO) and in those of North European (NE) origin *

\begin{tabular}{ll}
\hline & $\begin{array}{l}\text { Cumulative } \\
\text { adjusted } \\
r^{2}\end{array}$ \\
\hline Variables for patients IO & \\
Lp(a) lipoprotein (+) & $0 \cdot 21$ \\
Cholesterol (+) & $0 \cdot 35$ \\
Serum insulin (+) & $0 \cdot 41$ \\
High density lipoprotein cholesterol (-) & $0 \cdot 45$ \\
Waist hip ratio (+) & $0 \cdot 46$ \\
Triglyceride (+) & $0 \cdot 47$ \\
Variables for patients of NE origin & $0 \cdot 24$ \\
Lp(a) lipoprotein (+) & $0 \cdot 38$ \\
Serum insulin (+) & $0 \cdot 45$ \\
Cholesterol (+) & $0 \cdot 50$ \\
Triglyceride (+) & $0 \cdot 51$ \\
High density lipoprotein cholesterol (-) & $0 \cdot 52$ \\
Waist hip ratio (+) & \\
\hline *Variables in bold are significant independent predictors \\
(P 0.01) of the severity of coronary artery disease on multi- \\
variate analysis, ranked in descending order of the magnitude of \\
their incremental contribution to cumulative adjusted $r^{2}$. \\
+ , positive correlation. \\
-, negative correlation.
\end{tabular}

European origin group were 19, 27, and 36. Twenty eight of the young Indian origin group were Gujerati Hindu, 21 Punjabi Muslim, 16 Gujerati Muslim, and 24 Punjabi Sikhs. Seventy four (83\%) of the young Indian origin group were born in the United Kingdom. Table 6 gives the physical and behavioural features of the young adult groups. The waist hip ratio was greater in young adults of Indian origin, and alcohol intake was increased in those of North European origin. Current smoking habits were similar. Insulin and $\mathrm{Lp}(\mathrm{a})$ lipoprotein concentrations were higher in the young Indian origin group (table 7 ).

FATHER SON COMPARISONS

There was correlation in both ethnic groups between parental and filial insulin, $\mathrm{Lp}(\mathrm{a})$ lipoprotein, and total cholesterol concentrations (table 8). A relatively weaker correlation was observed for HDL cholesterol in each group, and for non-esterified fatty acid and waist hip ratio in participants of Indian origin.

Table 6 Physical, behavioural, and demographic features of sons (aged 15-30 years) of patients of Indian origin (IO) and of those of North European (NE) origin

\begin{tabular}{|c|c|c|}
\hline Variable & $\begin{array}{l}I O \\
(n=89)\end{array}$ & $\begin{array}{l}N E \\
(n=82)\end{array}$ \\
\hline $\begin{array}{l}\text { Age (years) } \\
\text { Current smokers (\%) } \\
\text { Alcohol (U/week) } \\
\text { Body mass index } \\
\left(\mathbf{k g} / \mathrm{m}^{2}\right)\end{array}$ & $\begin{array}{l}22 \cdot 1(21 \cdot 2-23 \cdot 2) \\
53(47-59) \\
7 \cdot 71(6 \cdot 05-8 \cdot 59) \\
24 \cdot 1(23 \cdot 6-24 \cdot 6)\end{array}$ & $\begin{array}{l}22 \cdot 8(21 \cdot 9-23 \cdot 8) \\
48(39-54) \\
10 \cdot 3(8 \cdot 38-12 \cdot 1) \\
24 \cdot 0(23 \cdot 6-24 \cdot 6)\end{array}$ \\
\hline $\begin{array}{l}\text { Waist hip ratio } \\
\text { Manual workers (\%) } \\
\text { Students (\%) } \\
\text { Non-manual } \\
\text { workers (\%) }\end{array}$ & $\begin{array}{l}0 \cdot 87(0 \cdot 85-0 \cdot 89) \\
31(26-36) \\
27(20-34) \\
42(38-46)\end{array}$ & $\begin{array}{l}0 \cdot 83(0 \cdot 81-0 \cdot 85) \\
36(29-43) \\
24(18-30) \\
40(36-44)\end{array}$ \\
\hline
\end{tabular}

Values are mean or percentage ( $95 \%$ confidence intervals). 
Table 7 Blood pressure and biochemical features of sons (aged 15-30 years) of patients of Indian origin (IO) and of those of North European (NE) origin

\begin{tabular}{lcc}
\hline Variable & $\begin{array}{l}I O \\
(n=89)\end{array}$ & $\begin{array}{l}N E \\
(n=82)\end{array}$ \\
\hline Systolic blood pressure (mm Hg) & $119 \cdot 6(115 \cdot 9-123 \cdot 4)$ & $125 \cdot 2(121 \cdot 2-125 \cdot 1)$ \\
Diastolic blood pressure (mm Hg) & $67 \cdot 9(65 \cdot 5-70 \cdot 1)$ & $71 \cdot 6(69 \cdot 1-74 \cdot 2)$ \\
Plasma glucose (mmol/) & $4 \cdot 4(4 \cdot 1-4 \cdot 6)$ & $4 \cdot 2(3 \cdot 9-4 \cdot 5)$ \\
Insulin (mU/1) & $14 \cdot 3(12 \cdot 9-15 \cdot 8)$ & $8 \cdot 43(7 \cdot 29-9 \cdot 60)$ \\
Cholesterol (mmol/l) & $4 \cdot 2(4 \cdot 0-4 \cdot 4)$ & $4 \cdot 1(4 \cdot 0-4 \cdot 2)$ \\
High density lipoprotein cholesterol (mmol/l) & $1 \cdot 2(1 \cdot 2-1 \cdot 3)$ & $1 \cdot 3(1 \cdot 2-1 \cdot 3)$ \\
Triglyceride (mmol/l) & $1 \cdot 6(1 \cdot 5-1 \cdot 7)$ & $1 \cdot 6(1 \cdot 5-1 \cdot 6)$ \\
Apolipoprotein B (mmol/l) & $88 \cdot 6(83 \cdot 4-93 \cdot 9)$ & $84 \cdot 6(79 \cdot 8-89 \cdot 6)$ \\
Lp(a) lipoprotein (mg/d) & $19 \cdot 1(16 \cdot 8-21 \cdot 8)$ & $10 \cdot 5(8 \cdot 3-12 \cdot 8)$ \\
Non-esterified fatty acid (mEq/l) & $0.39(0 \cdot 29-0 \cdot 49)$ & $0 \cdot 28(0 \cdot 21-0 \cdot 35)$ \\
\hline
\end{tabular}

Values are mean or percentage ( $95 \%$ confidence intervals) (adjusted for age and body mass index).
Table 8 Correlation of physiological and metabolic factors (adjusted for age and body mass index) in fathers and sons of Indian origin (IO) and in those of North European (NE) origin

\begin{tabular}{|c|c|c|}
\hline Variable & $N E$ & IO \\
\hline Waist hip ratio & 0.13 & $\begin{array}{l}0.31 \\
0.39\end{array}$ \\
\hline $\begin{array}{l}\text { Cholesterol } \\
\text { High density lipoprotein cholesterol }\end{array}$ & $\begin{array}{l}0.45 \\
0.37\end{array}$ & $\begin{array}{l}0 \cdot 39 \\
0 \cdot 28\end{array}$ \\
\hline Triglyceride & $0 \cdot 25$ & 0.12 \\
\hline Serum insulin & 0.49 & 0.41 \\
\hline Non-esterified fatty acids & $0 \cdot 23$ & 0.40 \\
\hline Apolipoprotein B & $0 \cdot 16$ & -0.03 \\
\hline Fasting glucose & $0 \cdot 11$ & $-0 \cdot 15$ \\
\hline Systolic blood pressure & 0.05 & -0.09 \\
\hline Diastolic blood pressure & 0.01 & 0.02 \\
\hline LP(a) lipoprotein & $0 \cdot 48$ & 0.44 \\
\hline
\end{tabular}

Values in bold indicate $\mathrm{P}<0.001$ and those in italic $\mathrm{P}<0.01$.

When sons were classified according to the severity of CAD in their fathers (table 9), differences were seen in the mean concentrations of the sons' total and HDL cholesterol, and especially of insulin and $\mathrm{Lp}(\mathrm{a})$ lipoprotein.

\section{Discussion}

We have shown that the extent of CAD in samples from the Indian origin and North European origin populations in Leicester undergoing coronary angiography is correlated in particular with concentrations of $\mathrm{Lp}$ (a) lipoprotein, insulin, and total cholesterol. The pattern of association was similar in each ethnic group. We have found a correlation, in both groups, between parental con- centrations of total and HDL cholesterol, insulin and $\mathrm{Lp}$ (a) lipoprotein, and the plasma or serum concentrations of these markers in their apparently healthy sons aged 15-30. Finally, we have demonstrated that while levels of most potential risk markers are broadly similar in young adults from the two groups, mean $\mathrm{Lp}$ (a) lipoprotein and insulin concentrations are significantly higher in those of Indian origin.

Our findings in respect of the correlation between the extent of angiographically determined coronary disease and risk marker levels are compatible with our own previous $s^{2} \mathrm{dy}^{3}$ and with the studies of Hughes et al, ${ }^{4}$ Lowry et $a l,{ }^{9}$ and Dhawan and Bray. ${ }^{10}$ The present study emphasises the predictive importance of $\mathrm{Lp}$ (a) lipoprotein and insulin in each ethnic group, and suggests that about half the observed variation in angiographic coronary disease score can be explained by these two variables plus cholesterol and triglyceride (table 5).

While it is accepted that patients undergoing coronary angiography are not necessarily representative of the whole community, the validity of raised total cholesterol, low $\mathrm{HDL}$ cholesterol, raised $\mathrm{Lp}$ (a) lipoprotein, ${ }^{11}{ }^{12}$ and raised fasting insulin concentrations ${ }^{1314}$ as CAD risk markers has been established by several studies using a variety of end points. The classification of coronary disease as minimal, single vessel, or multivessel, ${ }^{15}$ though crude, has proved to be a robust predictor of survival. ${ }^{16}$

Family history has long been acknowledged as a predictor of $\mathrm{CAD}$, and recent studies have further validated the concept. ${ }^{17} 18$ The concordance in risk marker patterns between parents with known CAD and their healthy children that we have demonstrated is likely to be a result of a combination of genetic and cultural factors. $\mathrm{Lp}(\mathrm{a})$ lipoprotein concentrations are thought to be largely determined as a consequence of genetic polymorphism. ${ }^{19}$ While polymorphism may also have a role in determining cholesterol and insulin concentrations, these are also susceptible to modification by factors such as diet and exercise. ${ }^{20}$

Table 9 Selected variables in sons of fathers of Indian origin (IO) and of North European (NE) origin classified according to severity of coronary artery disease (CAD) (adjusted for age and body mass index)

\begin{tabular}{|c|c|c|c|c|c|}
\hline $\begin{array}{l}\text { Offspring } \\
\text { variable }\end{array}$ & $\begin{array}{l}\text { No lesion } \\
(N E=19 ; I O=18)\end{array}$ & $\begin{array}{l}\text { Single vessel disease } \\
(N E=27 ; I O=30)\end{array}$ & $\begin{array}{l}\text { Multivessel disease } \\
(N E=36 ; I O=41)\end{array}$ & $\begin{array}{l}\text { Analysis of variance } \\
\text { of parental } C A D \\
\text { in each ethnic } \\
\text { group }(P \text { value } \\
\text { for trend })^{\star}\end{array}$ & $\begin{array}{l}\text { Analysis of variance } \\
\text { of parental CAD } \\
\text { with the remaining } \\
\text { variables as covariatest }\end{array}$ \\
\hline \multicolumn{6}{|c|}{ Waist hip ratio } \\
\hline $\begin{array}{l}\text { NE } \\
\text { IO }\end{array}$ & $\begin{array}{l}0.85(0.81-0.89) \\
0.85(0.81-0.89)\end{array}$ & $\begin{array}{l}0.83(0.81-0.85) \\
0.88(0.84-0.92)\end{array}$ & $\begin{array}{l}0.86(0.84-0.88) \\
0.89(0.85-0.93)\end{array}$ & $\begin{array}{l}0.19 \\
0.07\end{array}$ & $\begin{array}{l}0 \cdot 29 \\
0 \cdot 36\end{array}$ \\
\hline \multicolumn{6}{|c|}{ Cholesterol $(\mathrm{mmol} / \mathrm{l})$} \\
\hline $\begin{array}{l}\text { NE } \\
\text { IO }\end{array}$ & $\begin{array}{l}4 \cdot 1(3 \cdot 8-4 \cdot 4) \\
4 \cdot 3(4 \cdot 0-4 \cdot 6)\end{array}$ & $\begin{array}{l}4 \cdot 4(4 \cdot 2-4 \cdot 7) \\
4 \cdot 7(4 \cdot 4-5 \cdot 0)\end{array}$ & $\begin{array}{l}4 \cdot 7(4 \cdot 4-5 \cdot 0) \\
4 \cdot 9(4 \cdot 6-5 \cdot 1)\end{array}$ & $\begin{array}{l}0.01 \\
0.02\end{array}$ & $\begin{array}{l}0.09 \\
0.11\end{array}$ \\
\hline \multicolumn{6}{|c|}{ High density lipoprotein cholesterol (mmol/l) } \\
\hline $\begin{array}{l}\text { NE } \\
\text { IO }\end{array}$ & $\begin{array}{l}1.3(1.2-1.5) \\
1.4(1.2-1.5)\end{array}$ & $\begin{array}{l}1 \cdot 2(1 \cdot 1-1 \cdot 2) \\
1 \cdot 3(1 \cdot 2-1 \cdot 4)\end{array}$ & $\begin{array}{l}1 \cdot 2(1 \cdot 1-1 \cdot 2) \\
1 \cdot 2(1 \cdot 1-1 \cdot 2)\end{array}$ & $\begin{array}{l}0.01 \\
0.03\end{array}$ & $\begin{array}{l}0.04 \\
0.08\end{array}$ \\
\hline \multicolumn{6}{|c|}{ Insulin ( $\mu \mathrm{mol} / \mathrm{l})$} \\
\hline $\begin{array}{l}\text { NE } \\
\text { IO }\end{array}$ & $\begin{array}{l}8 \cdot 9(5 \cdot 1-12 \cdot 6) \\
8 \cdot 7(4 \cdot 2-13 \cdot 2)\end{array}$ & $\begin{array}{l}11 \cdot 2(8 \cdot 1-14 \cdot 6) \\
14 \cdot 5(10 \cdot 2-19 \cdot 2)\end{array}$ & $\begin{array}{l}16 \cdot 0(13 \cdot 6-18 \cdot 3) \\
20.5(17 \cdot 2-23 \cdot 9)\end{array}$ & $\begin{array}{l}0.004 \\
0.001\end{array}$ & $\begin{array}{l}0.03 \\
0 \cdot 01\end{array}$ \\
\hline \multicolumn{6}{|c|}{ Lp(a) lipoprotein (mg/dl) } \\
\hline $\begin{array}{l}\text { NÉ } \\
\text { IO }\end{array}$ & $\begin{array}{l}10 \cdot 7(4 \cdot 9-17 \cdot 8) \\
13 \cdot 0(5 \cdot 4-21 \cdot 3)\end{array}$ & $\begin{array}{l}14 \cdot 7(10 \cdot 8-18 \cdot 6) \\
21 \cdot 5(15 \cdot 1-28 \cdot 9)\end{array}$ & $\begin{array}{l}22 \cdot 1(17 \cdot 5-22 \cdot 8) \\
32 \cdot 5(27 \cdot 1-37 \cdot 8)\end{array}$ & $\begin{array}{l}0.006 \\
0.001\end{array}$ & $\begin{array}{l}0.01 \\
0.004\end{array}$ \\
\hline
\end{tabular}

${ }^{\star}$ Followed by Newman Keuls test. Variables were logarithmically transformed as described in the text. Values are mean ( $95 \%$ confidence intervals). $\dagger$ These are the remaining variables in table 9. 
Indeed, one of the reasons we were anxious to study the children of patients with angina was the possibility that reduced physical activity resulting from angina might itself alter the risk factor pattern. The replication of risk factor patterns in the asymptomatic younger generation discounts this hypothesis. In a recent pilot study we were able to show a significant correlation between insulin (but not $\mathrm{Lp}(\mathrm{a})$ lipoprotein) concentrations and levels of habitual physical activity in young relatives of CAD patients. ${ }^{21}$

Several studies ${ }^{22} 23$ have emphasised the importance of insulin resistance and central obesity as risk factors for $\mathrm{CAD}$ in the Indian origin community. Suggested causative factors have included heredity, physical inactivity, and possibly fetal or neonatal malnutrition. ${ }^{24}$ Previous studies have largely concentrated on older adults; the raised mean insulin and $\mathrm{Lp}$ (a) lipoprotein concentrations shown here in the young Indian origin group, for the most part born and raised in the United Kingdom, have worrying implications for the future incidence of $\mathrm{CAD}$, particularly as other risk marker levels are now comparable to their North European peers. Whether reduction of insulin concentrations by diet and exercise will reduce the incidence of $\mathrm{CAD}$ remains to be seen. Our results strongly support the concept that health promotion measures aimed at reducing the prevalence of CAD should include the adolescent and young adult populations, particularly those with a family history of CAD, or who come from communities in which this diagnosis is prevalent.

We thank Dr P N Durrington and Dr M Mackness for laboratory analyses, and Dr A F A Sayeed for his help in recruiting patients and their sons. The work was supported by a grant from the British Heart Foundation.

1 Balarajan $R$. Ethnic differences in mortality from ischaemic heart disease and cerbrovascular disease in England and Wales. BMF 1991;302:560-4.

2 Lowy AGJ, Woods KL, Botha JL. The effects of demographic shift on CHD mortality in a large migrant popu-
lation at high risk. $f$ Public Health Med 1991;13:276-80.

3 Shaukat N, de Bono DP. Clinical features, risk factors and referral delay in British patients of Indian and European origin with angina matched for age and extent of coroorigin with angina matched for age and
4 Hughes LO, Wojciechowski AP, Raftery EB. Relationship between plasma cholesterol and coronary artery disease in Asians. Atherosclerosis 1990;83:15-20.

5 Adolphson JL, Albers JJ. Comparison of two nephelometric methods for apoprotein AI and apoprotein B with standardised apoprotein AI and B radioimmunoassays. f Lipid Res 1989;30:597-603.

6 Durrington PN, Whicher JT, Warren C. A comparison of methods for immunoassay of apolipoprotein B in man. methods for immunoassay of ap.

7 Gordon C, Yates AP, Davies D. Evidence for a direct action of exogenous insulin on pancreatic islets of diabetic mice: islet response to insulin preincubation Diabetologia 1985;28:291-4.

8 Larsson B. Obesity and body fat distribution as predictors of coronary heart disease. In: Marmot MG, Eliot $P$, eds Coronary heart disease epidemiology. New York: Oxford Medical Publications, 1992.

9 Lowry PJ, Lamb P, Mace PJE. Coronary artery disease in Asians in Birmingham. Br Heart f 1984;52:610-3.

10 Dhawan J, Bray CL. Relationship between angiographically assessed coronary artery disease, plasma insulin levels and lipids in Asians and Caucasians. Atherosclerosis 1994;105:35-41.

11 Murai A, Miyahara T, Fujimoto KN, Matsuda $M$, Kameyama $M$. Lp(a) as a risk factor for coronary heart disease and cerebral infarction. Atherosclerosis $1986 ; 59$. 199-206.

12 Dahlen GH, Guyton JR, Attar M, Farmar JA, Kautz JA, Gotto AM. Association of levels of lipoprotein(a), plasma lipids and other lipoproteins with coronary artery disease documented by coronary angiography. Circulation 1986;74:758-65.

13 Pyorala K, Savolainen E, Kaukkola S, Haapaskoski J. High plasma insulin as a coronary disease risk factor. In Eschwege E, ed. Advances in diabetes epidemiology. INSERM symposium 22. Amsterdam: Elsevier, 1982. 149-55.

14 Hughes LO, Cruickshank JK, Wright J. Disturbances of insulin in British Asians and white men surviving myocardial infarction. BMf 1989;299:531-41.

15 Proudfit WL, Bruschke AVG, Sones FM. Natural history of obstructive coronary disease: ten year study of 601 of obstructive coronary disease: ten year study of 601
nonsurgical cases. Prog Cardiovasc Dis 1978;21:53-64.

16 Joint AHA/ACC Task Force: guidelines and indications for coronary artery bypass graft surgery. $\mathcal{F} \mathrm{Am}$ Coll Cardiol 1991;17:543-89.

17 Rissanen AM, Nikkila EA. Coronary artery disease and its risk factors in families of young men with angina pectoris and in controls. Br Heart $\mathcal{f} 1979 ; 39: 875-83$.

18 Dimsdale JE. Familial aggregation of coronary artery disease and its relation to known genetic risk factors. $A m \mathcal{F}$ Cardiol 1986;51:1804-11.

19 Drayna DT, Hegle RA, Hass PE, et al. Genetic linkage between lipoprotein(a) phenotype and a DNA polymorphism in the plasminogen gene. Genomics 1988;3:230-6.

20 Koivisto BA, Yiki-Jarvinen H, DeFronzo RA. Physical training and insulin sensitivity. Diabetes Metab Res 1988; 1:445-51.

21 Shaukat N, Douglas JT, Bennett JL, de Bono DP. Can physical activity explain the differences in insulin levels physical activity explain the differences in insulin levels and fibrinolytic activity between young Indo-origin and European relatives of patients
disease? Fibrinolysis 1995;9:55-63.

22 McKeigue PM, Ferrie JE, Pierpoint T, Marmot MG. Association of early onset coronary heart disease in South Asian men with glucose intolerance and hyperinsulinaemia. Circulation 1993;87:152-61.

23 McKeigue PM, Shah B, Marmot MG. Relation of central obesity and insulin resistance with high diabetes prevalence and cardiovascular risk in South Asians. Lance 1991;337:382-6.

24 Robinson S, Walton RJ, Clark PM, Barker DJP, Hales CN. The relation of fetal growth to plasma glucose in young men. Diabetologia 1992;35:444-6. 